\title{
Hepatic Adenoma Following Short Period of Oral Contraceptive Use
}

\author{
Chinwe C. Nduka, $M D$
}

Hepatic adenoma is a rare, benign tumor of the liver, and its occurrence has been strongly associated with use of oral contraceptives. An estimated 320 cases of hepatic adenoma are diagnosed each year, 282 of which are attributable to oral contraceptive use. ${ }^{1}$ This association was first suggested by Baum et al, ${ }^{2}$ who in 1973 reported seven cases of hepatic adenoma, all related to oral contraceptive use. This association has been supported by other publications. ${ }^{3,4}$ In women who have never used oral contraceptives or who have used them for less than 24 months, hepatocellular adenoma develops at an annual rate of 1 and 1.3 per million, respectively, for women aged 16 to 30 years and 31 to 44 years. ${ }^{1}$ Oral contraceptive-related hepatic adenoma has mostly been reported in women who used the pills for 2 years or longer.

This report describes hepatic adenoma in a 31 year-old woman who had been taking oral contraceptives for less than 24 interrupted months. The rarity of this entity makes it worth reporting.

\section{Case Report}

A 31-year-old female was admitted to the family medicine service through the emergency department on 18 November 1997. She complained of sudden-onset low-back pain and right upper quadrant as well as right shoulder pain. She had one episode of vomiting the morning after admission. She denied fever and any symptoms suggesting pelvic inflammatory disease. She gave a 21-year history of hypothyroidism subsequent to a partial thyroidectomy in 1976. She had used oral contraceptive pills for 1 year in 1988 and quit for 9 years. She resumed use of oral contraceptive pills in February 1997, 9 months before her admission. During a physical examination she appeared anxious and had a low-grade fever,

Submitted 4 July 1998.

From the Department Of Family Practice, Texas Tech University Health Sciences, El Paso. Requests for reprints should be addressed to Chinwe C. Nduka, MD, 524 Anasazi Ct, El Paso, TX 79912. tachycardia, and diffuse abdominal pain with tender hepatomegaly.

Her complete blood count showed leukocytosis with a normal differential. Her initial hemoglobin and hematocrit readings were $12.7 \mathrm{~g} / \mathrm{dL}$ and 36.4 percent, respectively, which dropped overnight to $9 \mathrm{~g} / \mathrm{dL}$ and 26.0 percent. Her platelets and clotting functions were normal, but her liver transaminase levels were elevated: alanine aminotransferase was $116 \mathrm{U} / \mathrm{L}$, and aspartate aminotransferase was $142 \mathrm{U} / \mathrm{L}$. Amylase and lipase levels were normal. A serum pregnancy test was negative.

An abdominal sonogram done on admission showed a contracted gall bladder and inhomogeneous echotexture of the liver. She was initially treated for acute cholecystitis. A hepatobiliary scan done on the same day showed a nonemptying but well-visualized gall bladder and a large cold area occupying much of the right lobe of the liver. A repeated abdominal sonogram done on day 2 showed a huge hematoma within the right lobe of the liver, measuring $11.8 \times 7.8 \times 8.9 \mathrm{~cm}$, plus a small subcapsular hematoma. A ruptured hepatic adenoma was suspected with focal nodular hyperplasia as a differential diagnosis. A computerized tomographic (CT) scan of the abdomen was obtained on day 3 , which confirmed a hematoma in the right lobe of the liver, measuring $7.5 \times 7.5 \times 10 \mathrm{~cm}$, and large subcapsular hematoma with evidence of hemoperitoneum (Figure 1).

She underwent an emergency laparotomy with excision of the adenoma on day 3 . Intraoperative findings included a necrotic liver with massive intra-abdominal bleeding. The postoperative course was complicated by mild acute respiratory distress syndrome and acute tubular necrosis. The pathology report described necrotic tissue with compressed sinusoids. The central veins and portal triads were not readily recognized. Peliosis hepatis was observed. Subsequently, the patient did very well and recovered renal and pulmonary functions. 


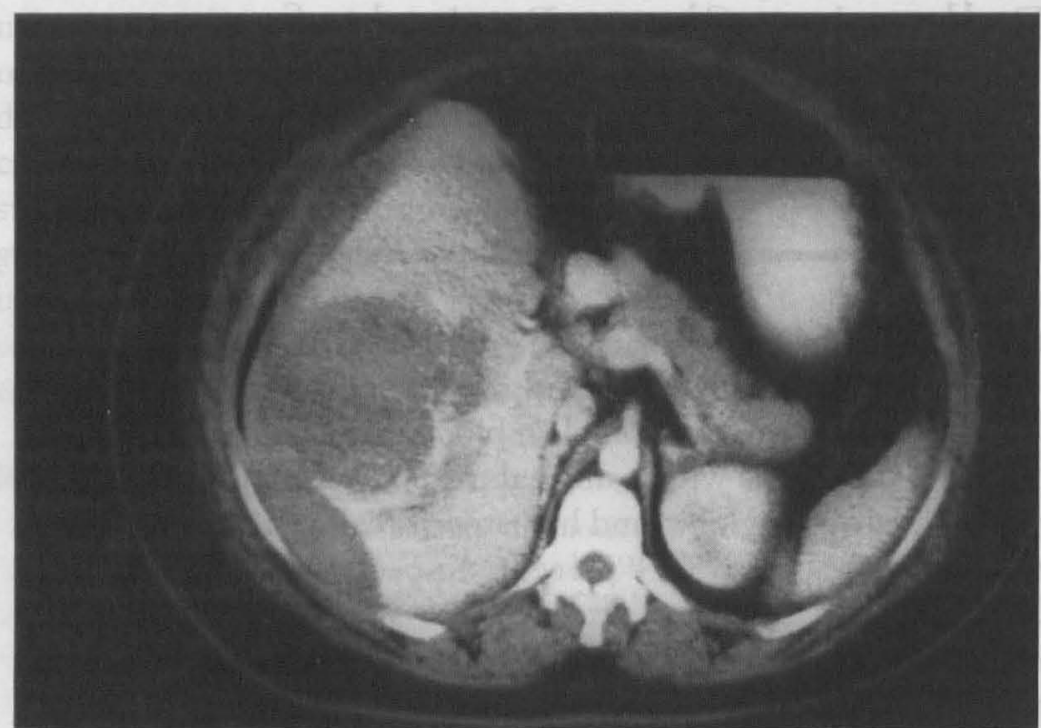

Figure 1. Computed tomographic scan of abdomen showing large intraparenchymal hematoma in the liver measuring $7.5 \times 7.5 \times 10 \mathrm{~cm}$. Seen also is large subcapsular hemorrhage with evidence of hemoperitoneum.

asymptomatic. A causal relation has not been established between focal nodular hyperplasia and oral contraceptives.

The finding of a hematoma on imaging studies supports the diagnosis of hepatic adenoma. ${ }^{5} \mathrm{~A}$ sonogram might show a hypoechoic, hyperechoic, or isoechoic lesion in either hepatic adenoma or focal nodular hyperplasia. ${ }^{11}$ An avascular central scar found on magnetic resonance imaging (MRI) supports the diagnosis of focal nodular hyperplasia. Because focal nodular hyperplasia is a vascular tumor, labeled colloid uptake on scintigraphy is normal or increased. ${ }^{5}$ A CT scan is useful in confirming a hematoma.

\section{Discussion}

\section{Epidemiology}

Development of hepatic adenoma is related to the strength of oral contraceptives used and the duration of use, as well as to patient age of older than 30 years. ${ }^{1}$ Its incidence has fallen since the introduction of pills containing smaller amounts of estrogen. Nagorney ${ }^{5}$ reviewed the case histories of 22 women who had a diagnosis of hepatic adenoma between 1989 and 1993 and found the median duration of oral contraceptive use to be 14 years. Hepatic adenoma can occur singly or in multiples in association with glycogen storage disease. Multiple adenomas are linked more often with glycogen storage disease. ${ }^{6,7}$ Danazol has also been linked with development of hepatic adenomas. ${ }^{8}$ Familial adenomas have been suggested. ${ }^{1}$ Very rarely has hepatic adenoma been documented in male patients. ${ }^{5,9}$

\section{Diagnosis}

When making the diagnosis, it is important to distinguish between hepatic adenoma and focal nodular hyperplasia. Asymptomatic hepatic adenoma is unusual. ${ }^{10}$ Rooks et al ${ }^{1}$ found in their case review of this condition that 34 percent of patients had intraperitoneal bleeding, 15 percent had hemorrhage into the tumor, 47 percent complained of abdominal mass, and 19 percent had episodic or vague abdominal pain. In contrast, most patients with focal nodular hyperplasia are
Hepatic adenomas lack Kupffer cells and therefore do not take up colloid on a technetium sulfur colloid scan. ${ }^{4}$ Histologically, bile ducts and portal tracts are conspicuously absent in hepatic adenoma, and occasional peliosis hepatis will be noted. A central stellate scar found on pathologic examination is characteristic of focal nodular hyperplasia.

\section{Treatment}

All literature reviewed support excision of the adenoma in case of intratumoral or intraperitoneal hemorrhage. Management of asymptomatic cases remains controversial, however. It is important to keep in mind that (1) malignant transformation of hepatic adenomas has been documented, ${ }^{12-14}$ and (2) bleeding into lesions of less than $5 \mathrm{~cm}$ has been reported. 7,15 There is as yet no consensus on the behavior of this lesion after the patient stops oral contraceptive therapy. Some authors have reported tumor regression in some of their patients ${ }^{16}$; others have not. ${ }^{5,17}$

Authors who concur with the theory of regression advocate discontinuation of steroids and observation for the asymptomatic patient. ${ }^{16}$ In the opinion of others, focal nodular hyperplasia implies a benign condition and warrants observation and oral contraceptive withdrawal, whereas hepatic adenoma implies unpredictability and warrants resection. ${ }^{7,13}$ This approach is welcomed by several other authors, some of whom advise excision of 
adenomas larger than 5 to $10 \mathrm{~cm}$ or adenomas that fail to regress within 6 months of discontinuation of oral contraceptives. ${ }^{17,18} \mathrm{~A}$ more aggressive group, considering the risk of hemorrhage and possible malignant transformation, advocates surgical excision regardless of size and symptoms. ${ }^{711,19,20}$ For high-risk asymptomatic patients who have bilobar involvement or patients who will require major hepatic resection, a conservative approach, with cessation of oral contraceptive therapy and close follow-up, is advised. ${ }^{19}$

\section{Conclusion}

Physicians need to be aware of the adverse effects of oral contraceptive therapy including, but not limited to, hepatic adenoma. Though rare, patients can develop this complication after using oral contraceptives for as briefly as 1 year. It is essential that family physicians are on the lookout for this condition and familiarize themselves with appropriate management options.

\section{References}

1. Rooks JB, Ory WH, Ishak KG, Strauss LT, Greenspan JR, Hill AP, et al. Epidemiology of hepatocellular adenoma. The role of oral contraceptive use. JAMA 1979;242:644-8.

2. Baum JK, Bookstein JJ, Holtz F, Klein EW. Possible association between benign hepatomas and oral contraceptives. Lancet 1973;2:926-9.

3. Edmondson HA, Henderson B, Benten B. Liver-cell adenomas associated with use of oral contraceptives. N Engl J Med 1976;294:470-2.

4. Kerlin P, Davis GL, McGill DB, Weiland LH, Adson MA, Sheedy PF 2 nd. Hepatic adenoma and focal nodular hyperplasia: clinical, pathologic, and radiologic features. Gastroenterology $1983 ; 84(5 \mathrm{Pt} \mathrm{1})$ : 994-1002.

5. Nagorney DM. Benign hepatic tumors: focal nodular hyperplasia and hepatocellular adenoma. World J Surg 1995;19:13-8.

6. Howell RR, Stevenson RE, Ben-Menachem Y, Phyliky RL, Berry DH. Hepatic adenomata with type I glycogen storage disease. JAMA 1976;236:1481-4.

7. Leese T, Farges O, Bismuth H. Liver cell adenomas. A 12-year surgical experience from a specialist hepato-biliary unit. Ann Surg 1988;208:558-64.

8. Fermand JP, Levy Y, Bouscary D, D'Agay MF, Clot
P, Frija J, et al. Danazol-induced hepatocellular adenoma. Am J Med 1990;88:529-30.

9. Gonzalez A, Canga F, Cardenas F, Castellano G, Garcia H, Cuenca B, et al. An unusual case of hepatic adenoma in a male. J Clin Gastroenterol 1994; 19:179-81.

10. Chen PN, Shin JS, Lin XZ. Hepatic adenoma: an observation from asymptomatic stage to rupture. Hepatogastroenterology 1996;43:245-8.

11. Cherqui D, Rahmouni A, Charlotte F, Boulahdour $\mathrm{H}$, Metreau JM, Meignan M, et al. Management of focal nodular hyperplasia and hepatocellular adenoma in young women: a series of 41 patients with clinical, radiological, and pathological correlations. Hepatology 1995;22:1674-81.

12. Gyorffy EJ, Bredfeldt JE, Black WC. Transformation of hepatic cell adenoma to hepatocellular carcinoma due to oral contraceptive use. Ann Intern Med 1989;110:489-90.

13. Gordon SC, Reddy KR, Livingstone AS, Jeffers LJ, Schiff ER. Resolution of a contraceptive-steroid-induced hepatic adenoma with subsequent evolution into hepatocellular carcinoma. Ann Intern Med 1986;105:547-9.

14. Neuberger J, Portmann B, Nunnerly HB, Laws JW, Davis M, Williams R. Oral contraceptive-associated liver tumors: occurrence of malignancy and difficulties in diagnosis. Lancet 1980;1:273-6.

15. Flejou J, Barge J, Menu Y, Degott C, Bismuth $H$, Potet $\mathrm{F}$, et al. Liver adenomatosis. An entity distinct from liver adenoma? Gastroenterology 1985;89: 1132-8.

16. Edmondson HA, Reynolds TB, Henderson B, Benton $B$. Regression of liver cell adenomas associated with oral contraceptives. Ann Intern Med 1977;86: 180-2.

17. Marks WH, Thompson N, Appleman H. Failure of hepatic adenomas (HCA) to regress after discontinuance of oral contraceptives. An association with focal nodular hyperplasia (FNH) and uterine leiomyoma. Ann Surg 1988;208:190-5.

18. Malt RA. Surgery for hepatic neoplasms. N Engl J Med 1985;313:1591-6.

19. Nichols FC, Van Heerden JA, Weiland LH. Benign liver tumors. Surg Clin North Am 1989;69: 297-314.

20. Becker Y'T, Raiford DS, Webb L, Wright JK, Chapman WC, Pinson CW. Rupture and hemorrhage of hepatic focal nodular hyperplasia. Am Surg 1995;61: 210-4. 